\title{
Retrospective study of the implementation of the nursing process in a health area
}

\author{
Joseba Xabier Huitzi-Egilegor ${ }^{1}$ \\ Maria Isabel Elorza-Puyadena ${ }^{1}$ \\ Jose Maria Urkia-Etxabe ${ }^{2}$ \\ Maria Victoria Esnaola-Herrero ${ }^{3}$ \\ Carmen Asurabarrena-Iraola ${ }^{4}$
}

\begin{abstract}
Objectives: to analyze when the nursing process began to be used in the public and private healthcare centers of Gipuzkoa (Basque Country), and when both NANDA-I nursing diagnoses and the NIC-NOC terminologies were incorporated into this process. Method: a retrospective study was conducted, based on the analysis of nursing records that were used in the 158 studied centers. Results: the specific data provided showed that in Gipuzkoa, the nursing process began to be used in the 1990s. As for NANDA-I nursing diagnoses, they have been used since 1996, and the NIC-NOC terminologies has been used since 2004. Conclusion: it was concluded that public centers are the ones which, generally speaking, first began with the nursing methodology, and that in comparison to the United States and Canada, the nursing process started to be used about 20 years later, NANDA-I nursing diagnoses around 15 years later, and the NIC-NOC terminologies, around six years later.
\end{abstract}

Descriptors: Nursing Process; Nursing Diagnosis; History of Nursing; Nursing Methodology Research.

\footnotetext{
${ }^{1}$ PhD, Full Professor, Departamento de Enfermería II, Escuela de Enfermería de Donostia-San Sebastián, Universidad del País Vasco - Euskal Herriko Unibertsitatea, Donostia-San Sebastián, Spain.

${ }^{2}$ PhD, Full Professor, Departamento de Física Teórica e Historia de la Ciencia, Universidad del País Vasco - Euskal Herriko Unibertsitatea, DonostiaSan Sebastián, Spain.

${ }^{3} \mathrm{PhD}$, Technical Environment, Ayuntamiento de Donostia-San Sebastián, Donostia-San Sebastián, Spain.

${ }^{4} \mathrm{PhD}$, Collaborating Profesor, Departamento de Enfermería II, Escuela de Enfermería de Donostia-San Sebastián, Universidad del País Vasco Euskal Herriko Unibertsitatea, Donostia-San Sebastián, Spain.
} 


\section{Introduction}

The nursing process is the working method used by nursing to provide care ${ }^{(1)}$. Its creation dates back to the years 1950-1960 in the United States and Canada. It was during this time that the idea of nursing actions not being isolated actions, but rather as part of a process, began to take off(2).

In the early years it was implemented and developed, especially in the field of education, namely, in schools of nursing. In the 1970s, its use was extended to clinical practice (professional practice) ${ }^{(3)}$.

The nursing process consisted, initially, of three stages, and subsequently, four stages. Finally, between the years 1973-1975, the concept of nursing diagnosis was agreed( ${ }^{(4)}$, and an initial list of such diagnoses was published by NANDA-I ${ }^{(5)}$. It was then that the current five stages were reached: the assessment stage, the diagnosis stage, the planning stage, the implementation stage and, finally, the evaluation stage.

Later, in 1992, the first edition of the Nursing Interventions Classification (NIC) ${ }^{(6)}$ was published, and the first edition of Nursing Outcomes Classification $(\mathrm{NOC})^{(7)}$ in 1998; both of these terminologies improved the nursing process.

Currently, the methodology of the nursing process is used in healthcare centers around the world(8-9), and its use is associated with improvements in the quality of information, in inter-profesional communication, and in the measuring of nursing performance ${ }^{(10)}$.

In the area of Spain, the papers found suggested that the use of the nursing process began to spread in the $1990 \mathrm{~s}^{(11-13)}$ and that it is widespread today ${ }^{(14)}$. Cross-sectional studies that analyzed the application of the nursing process in a specific area or region were found(15-16), one of them conducted in the health area of Gipuzkoa. However, retrospective studies that provided specific dates and data about the progression of its implementation were not found.

The objective of this paper was to study when the nursing process began to be used in public and private healthcare centers of Gipuzkoa (Basque Country) and when the NANDA-I nursing diagnoses and the NIC-NOC terminologies were incorporated into said process. The results will help in understanding the evolution of the working method of nursing in Gipuzkoa.

\section{Method}

A retrospective study was performed on nursing records that were used in public and private health care centers in the region of Gipuzkoa, one of the three areas of health within the Basque Country.

A total of 158 centers were studied: 137 public (all of them) and 21 private (all those which had ten or more nursing professionals on staff). In these 158 centers, 2667 nursing professionals were employed (2013 in public centers, and 564 in private centers), representing around $90 \%$ of all professionals working in clinical practice in Gipuzkoa.

The obtaining or viewing of the nursing records was performed after obtaining the approval of the directors of the centers involved and after interviewing the people responsible for those records. In the publishing of the data, the anonymity of the centers has been maintained.

The Research Ethics Committee of the University Euskal Herriko Unibertsitatea of the Basque Country EHU (UPV-EHU) began operating in 2010. The collection of data for this study occurred between January and December 2009, so a validation report by the mentioned committee could not be obtained.

There were three issues that were studied: the year in which the nursing process began to be used, the year in which the process incorporated NANDA-I nursing diagnosis, and the year in which this process incorporated the NIC-NOC terminologies.

The criterion used to determining whether or not the nursing process was applied in a given center was the existence of a nursing record corresponding to the assessment stage of the nursing process, as the other stages are based on this first stage $\mathrm{e}^{(1,17)}$. Therefore, if the nursing assessment record was present, the nursing process was considered to be applied.

The criterion to consider that NANDA-I nursing diagnoses were incorporated into the nursing process was the confirmation of the existence of that section within the nursing records.

The criterion to consider that the NIC-NOC terminologies were incorporated into the nursing process was the confirmation of their use during the writing of nursing interventions and nursing outcomes within the nursing records.

A quantitative analysis of the data using descriptive statistics was performed.

\section{Results}

Table 1 shows which centers were studied, the number of nursing professionals that worked in them, the year in which the nursing process began to be used, the year in which the process incorporated NANDA-I 
nursing diagnoses, and the year in which the process incorporated the NIC-NOC terminologies. The number of nurses working in each center shows the magnitude (size) of the center.

Table 1 - Centers studied, the number of nursing professionals that worked in them, the year in which the nursing process (NP) began to be used, the year in which the process incorporated NANDA-I nursing diagnoses (ND), and the year in which the process incorporated the NIC-NOC terminologies. When the box is empty, it means that the facility did not use the that particular item

\begin{tabular}{|c|c|c|c|c|c|}
\hline $\begin{array}{c}\text { Health System } \\
\text { and Area }\end{array}$ & $\begin{array}{c}\text { Number of } \\
\text { centers }\end{array}$ & $\begin{array}{c}\text { Number of } \\
\text { professional } \\
\text { nurses }\end{array}$ & $\begin{array}{l}\text { Year use of } \\
\text { NP began }\end{array}$ & $\begin{array}{l}\text { Year use of } \\
\text { ND began }\end{array}$ & $\begin{array}{c}\text { Year use of } \\
\text { NIC-NOC } \\
\text { began }\end{array}$ \\
\hline Public Health system & 137 & 2103 & & & \\
\hline Primary care & 116 & 514 & 2004 & 2004 & 2004 \\
\hline Specialized care & 5 & 1523 & 1990 & 1996 & 2008 \\
\hline Hospital num. 1 & 1 & 1072 & 1990 & 1996 & 2008 \\
\hline Hospital num. 2 & 1 & 110 & 1990 & 1996 & 2008 \\
\hline Hospital num. 3 & 1 & 111 & 1990 & 1996 & 2008 \\
\hline Hospital num. 4 & 1 & 143 & 1990 & 1996 & 2008 \\
\hline Hospital num. 5 & 1 & 87 & 1990 & 1996 & 2008 \\
\hline Mental Health & 15 & 54 & & & \\
\hline Psychiatry Service Hospital num. 1 & 1 & 22 & 1990 & 1996 & 2008 \\
\hline Outpatient care centers & 14 & 32 & 2007 & 2007 & - \\
\hline Gerontology and geriatrics & 1 & 12 & 1990 & - & - \\
\hline Private health system & 21 & 564 & & & \\
\hline Specialized care & 6 & 410 & & & \\
\hline Hospital num. 1 & 1 & 35 & - & - & - \\
\hline Hospital num. 2 & 1 & 85 & - & - & - \\
\hline Hospital num. 3 & 1 & 40 & 2003 & - & - \\
\hline Hospital num. 4 & 1 & 50 & 1993 & - & - \\
\hline Hospital num. 5 & 1 & 165 & - & - & - \\
\hline Hospital num. 6 & 1 & 35 & 2004 & 2004 & - \\
\hline Mental Health & 4 & 69 & & & \\
\hline Hospital num. 1 & 1 & 25 & 1992 & - & - \\
\hline Hospital num. 2 & 1 & 22 & 1998 & 2005 & 2008 \\
\hline Hospital num. 3 & 1 & 12 & 2005 & 2005 & 2008 \\
\hline Hospital num. 4 & 1 & 10 & 2001 & - & - \\
\hline Gerontology and geriatrics & 11 & 85 & & & \\
\hline Geriatric center num. 1 & 8 & 55 & 1982 & 1996 & - \\
\hline Geriatric center num. 2 & 1 & 10 & 1999 & 1999 & - \\
\hline Geriatric center num. 3 & 1 & 10 & 2002 & - & - \\
\hline Geriatric center num. 4 & 1 & 10 & 1994 & - & - \\
\hline
\end{tabular}

According to the figures in Table 1, the use of the nursing process began, with one exception, in 1990 and became widespread in the 2000s. The inclusion of NANDA-I nursing diagnoses in the process began to occur in 1996, and in regard to the incorporation of the NIC-NOC terminologies(19-20), their implementation first began in 2004.

Noting the number of centers and the number of professionals working in them, we can say that both the use of the nursing process, as well as the use of NANDA-I nursing diagnoses and the NIC-NOC terminologies are, today, a reality in the majority of settings. The current utilization figures were released in a cross sectional study already published(16).

Reading by area of activity, it is observed that, generally speaking, the public specialty care area first began to apply the nursing process and, moreover, was a pioneer in incorporating both NANDA-I nursing diagnoses, and the NIC-NOC terminologies. On the contrary, the area of private specialized care was the one which presented the least development.

In the mental health area, the introduction of the nursing process occurred somewhat later, both in public and private centers, and the use of NANDA-I diagnoses 
and NIC-NOC terminologies has not yet been fully incorporated into all centers.

In the area of gerontology and geriatrics, we observe, first, that the first center of Gipuzkoa that implanted the nursing process was a private center in this area, but on the other hand, there were large differences between the centers in the start dates, and it coincides that none of them incorporated the NIC-NOC terminologies, and only half of them have incorporated NANDA-I nursing diagnoses.

In centers where many nurses worked, pilot tests were conducted before the nursing process began. For example, in the area of public specialized care, pilot tests were conducted between the years 1988-1989, and the process began in 1990. In another example, in the area of public primary care, pilot tests were conducted between the years 1999-2003, and the initial use of the process began in 2004. Therefore, the decision to begin the nursing process occurred two to three years prior to the date shown in the table.

\section{Discussion}

The results showed that in Gipuzkoa, the nursing process began to be applied 20 years later than in the United States of America and Canada: in these countries the nursing process began to be applied in practice in the $1970 s^{(3)}$; in Gipuzkoa, it began in the 1990s.

In comparison with Spain, Gipuzkoa's results are similar: in Spain, the nursing process started in the $1990 s^{(11-13)}$; this occurred in Gipuzkoa, as well.

The delay of 20 years behind America may be related to the delay observed in the teaching of nursing process in nursing schools. In the U.S.A., this began to be taught in the years 1950-1960. It occurred in Spain in the late 1970s: it was in 1977 when the nursing studies reached the university level(21) and the curricula began to include the teaching of nursing process ${ }^{(22)}$. The twenty-year delay observed when starting to teach the nursing process in nursing schools was observed when applying the nursing process in practice. It is thought that it was necessary that the nursing process was first incorporated into teaching in order to implement it within practice.

Regarding the incorporation of NANDA-I nursing diagnoses in the nursing process, the delay observed with respect to the United States of America and Canada was around 15 years, since the beginning of the use of diagnoses there was between the late 1970 s and early 1980s(3), and in Gipuzkoa it occurred after 1996. In comparison to Spain, there is no difference: in both cases the use of the diagnoses began in the $1990 \mathbf{s}^{(13,15)}$.

As for the inclusion of the NIC-NOC terminologies in the nursing process, the delay of Gipuzkoa in comparison to America was around six years. Given that it was in 1992 when the first edition of the Nursing Interventions Classification (NIC) ${ }^{(6)}$ was published, and that it was in the year 1998 when the first edition of the Nursing Outcomes Classification (NOC) ${ }^{(7)}$ was published, we used 1998 as the year in which these terminologies began to be used in the United States of America and Canada, while in Gipuzkoa they started to be used beginning in 2004 .

When analyzing the delays in implementing nursing methodology in comparison to the United States, it was observed that the time required to incorporate these novelties is decreasing: the nursing process was implemented in Gipuzkoa 20 years after arising in America, nursing diagnoses arrived 15 years later, and the NIC-NOC terminologies only six years later. It was concluded that there was increasing ease of incorporating novelties with respect to the nursing process.

Moreover, it is noteworthy that in all public centers in the same area, the application of the nursing process or the incorporation of novelties occurred simultaneously, while in private centers the difference between them was very large. This is because in public centers the direction of each area, which is what drove the changes, was unified. Instead, the directions of the private centers were independent, with no connections between them.

Finally, it should be noted that public centers were the ones that, on a widespread basis, began to apply the nursing methodology first, and it is in these centers that this methodology has been more developed. One reason may be that in Spain, the public health system has had more human and material resources than the private system $^{(23)}$. The more resources there are, the easier it is to implement new working methodologies.

\section{Conclusions}

The results of this study showed that in Gipuzkoa, the nursing process began to be applied in the 1990s. As for the incorporation of NANDA-I nursing diagnoses in the nursing process, it was initiated in 1996, and as for the inclusion of the NIC-NOC terminologies, their implementation began in 2004

The public centers were those which, on a widespread basis, began to apply the nursing methodology, and were the ones which had developed it more. 
Finally, this work shows that the novelties concerning the nursing process were incorporated more rapidly every time, and that the delay compared to the United States of America and Canada is declining.

\section{References}

1. Alfaro-Lefevre R. Applying nursing process: promoting collaborative care. Philadelphia: Lippincott; 2002.

2. De la Cuesta C. The Nursing Process: from development to implementation. J Adv Nurs. 1983;8:365-71.

3. Lavin MA, Meyer G, Carlson JH. A review of the use of nursing diagnosis in U.S. Nurse Practice Acts. Nurs Diag. 1999;10(2):57-64.

4. Yura $\mathrm{H}$, Walsh MB. The nursing process. 3 ed. Nueva York: Appleton-Century-Crofts; 1978.

5. Gebbie KM, Lavin MA. Classifying nursing diagnoses. Am J Nurs. 1974; 74:250-253.

6. Iowa Outcomes Project. Nursing Interventions Classification (NIC). St. Louis: Mosby; 1992.

7. Iowa Outcomes Project. Nursing Outcomes Classification (NOC). St. Louis: Mosby; 1997.

8. Müller-Staub M, Lavin MA, Needham I, Van Achterberg

T. Nursing diagnoses, interventions and outcomes application and impact on nursing practice: systematic review. J Adv Nurs. 2006;56(5):514-31.

9. Lunney M. Critical thinking and accuracy of nurses diagnosis. Int J Nurs Terminol Classif. 2003;14(3):96-107. 10. Urquhart C, Currell R, Grant MJ, Hardiker NR. Nursing record systems: effects on nursing practice and healthcare outcomes. Cochrane Database of Systematic Reviews 2009; [acesso 22 set 2011]; Issue 1. Art. No.: CD002099. DOI: 10.1002/14651858.CD002099. pub2. Disponivel em: http://onlinelibrary.wiley.com/ doi/10.1002/14651858.CD002099.pub2/pdf/abstract

11. García-Carpintero J, Piñón M. ¿Por qué no siempre funciona el PAE? Rol Enferm. 1994;195:63-6.

12. Martín E, García F, Asenjo A. Diagnósticos de enfermería. Estrategias de implantación. Rol Enferm. 1997;225:57-63.

13. Cuesta A, Luis MT, González P, Germán C, Coscollá $E$, Benavent $M A$, et al. El diagnóstico de enfermería en España, ¿una realidad apreciable? Index Enferm. 1995; [acesso 21 maio 2011];12-13. Disponivel em: http:// www.index-f.com/index-enfermeria/12-13/1423.php

14. González MA. Normalización de la práctica enfermera como contribución a la salud, la calidad asistencial y la seguridad clínica de las personas. [tesis doctoral]. Madrid: Consejo General de Colegios Oficiales de Enfermería de España; 2006.
15. Izquierdo JM, Pérez MB, Ramírez FJ, Serrano I, Torres MD, Conde G. Implantación del proceso enfermero. Rol Enferm. 2002;25(7-8):488-93.

16. Huitzi-Egilegor JX, Elorza-Puyadena MI, Urkia-Etxabe $J M$, Zubero-Linaza J, Zupiria-Gorostidi $X$. Use of the nursing process at public and private centers in a health area. Rev. Latino-Am. Enfermagem. 2012;20(5):903-8. 17. Giménez AM, Serrano P. Imprecisiones del proceso diagnóstico enfermero. Metas Enferm. dic 2008/ene 2009;11(10):57-62.

18. NANDA-International. Nursing diagnoses. Definitions and classification 2012-2014. Oxford: WileyBlackwell; 2012.

19. Moorhead S, Johnson M, Maas ML, Swanson E. Nursing outcomes classification (NOC). 5 ed. Saint Louis: Elsevier Health Sciences; 2012.

20. Bulechek GM, Butcher HK, Dochterman JM, Wagner C. Nursing interventions classification (NIC). 6 ed. St. Louis: Elsevier Health Sciences; 2012.

21. Real Decreto 2128/1977 de 23 de julio (ES). Sobre integración en la Universidad de las Escuelas de Ayudantes Técnicos Sanitarios como Escuelas Universitarias de Enfermería. BOE. 1977;(200):18716-7.

22. Fernández $C$, Garrido $M$, Santo Tomás M, Serrano MD. Enfermería Fundamental. Barcelona: Masson. Master de Enfermería; 2000.

23. De Manuel E, De Oleaga JI. Sistemas de salud en los países desarrollados. In: Martín Zurro A, Cano Pérez JF, editors. Atención Primaria. Conceptos, organización y práctica clínica. 5 ed. Madrid: Elsevier; 2003. p. 16-46. 